\title{
ECSS \\ One-Step Electrodeposition of Nanosized Cobalt Oxy/Hydroxide Composites Obtained from Deep Eutectic Solvent as Multifunctional Catalysts
}

\author{
Alan M. P. Sakita, ${ }^{1,2, z}$ Rodrigo Della Noce, ${ }^{3,4}$ Assis V. Benedetti, ${ }^{1, z}$ \\ Jaume Garcia-Amorós, 5 and Elisa Vallés ${ }^{2,6}$ \\ ${ }^{1}$ Instituto de Química, UNESP-Universidade Estadual Paulista, 14800-900 Araraquara, Brazil \\ ${ }^{2}$ Ge-CPN (Thin Films and Nanostructures Electrodeposition Group), Dpt. Ciència de Materials i Química Física, \\ 08028 Barcelona, Spain \\ ${ }^{3}$ Faculdade de Química, Instituto de Ciências Exatas e Naturais, Universidade Federal do Pará, $66075-110$ Belém - \\ PA, Brazil \\ ${ }^{4}$ Centro de Química Estrutural-CQE, Departament of Chemical Engineering, Instituto Superior Técnico, Universidade \\ de Lisboa, 1049-001 Lisboa, Portugal \\ ${ }^{5}$ Grup de Materials Orgànics, Institut de Nanociència i Nanotecnologia (IN2UB), Departament de Química \\ Inorgànica i Orgànica (Secció de Química Orgànica), Universitat de Barcelona, E-08028 Barcelona, Spain \\ ${ }^{6}$ Institute of Nanocience and Nanotechnology (IN2UB), Universitat de Barcelona, Barcelona, Spain
}

\begin{abstract}
Glyceline deep eutectic solvent, with a controlled amount of water, has been demonstrated as a useful medium for the electrochemical production of oxidized species of cobalt enabling, in turn, the use of this kind of solutions to electrodeposit species different than metals and alloys. The oxidized species have been fabricated directly over glassy carbon and nickel substrates in a single step with the concomitant formation of a poly-glycerol porous structure integrating the metallic oxides. Remarkably, the resulting composite (polymer + oxides) can be exploited as a multifunctional heterogeneous catalyst. On one hand, our composite material is an excellent and readily preparable electrode for the non-enzymatic amperometric detection and quantification of glucose. On the other hand, the composites reported herein are also efficient catalysts for the oxygen evolution reaction (OER) in alkaline solutions, displaying their maximum activity after the dissolution of the polymer and subsequent liberation of the oxidized cobalt species.

(C) 2018 The Electrochemical Society. [DOI: 10.1149/2.0261807jes]
\end{abstract}

Manuscript submitted February 7, 2018; revised manuscript received March 21, 2018. Published April 24, 2018.

The generation of cheap and effective catalysts for sensing, clean energy production, remediation or chemical synthesis, is currently the focus of attention of many researchers. ${ }^{1,2}$ Even though this kind of materials is in high demand, its preparation involves generally multi-step, expensive, and poorly efficient protocols. ${ }^{3-6}$ On this basis, the development of straightforward methods for their production is essential. Electrochemical methods have been widely used for the preparation of a diversity of active materials since they simplify significantly their synthesis and imply a lower economic cost. ${ }^{7,8}$ In this context, the electro-production of specific catalysts has become one of the priority aims of investigation within materials science during recent years. In addition, if the development of such simple electrochemical preparation schemes evolves in the creation of novel catalysts exhibiting multifunctionality, the challenge to tackle is even more motivating. ${ }^{9-12}$

Oxidized species of iron, cobalt and nickel of different nature (pure and mixed oxides, oxy/hydroxides, layered double hydroxides of the metals, or alloys) and structure (e.g. supported nanoparticles, films and platelets) have been proposed as catalysts for specific reactions, including the oxygen evolution reaction ${ }^{13-16}$ (involved in the generation of energy by water splitting), the oxidation of alcohols in fuel cells, ${ }^{17-19}$ capacitors $^{20-22}$ or the sensing of organic molecules. ${ }^{23,24}$ In all these instances, the catalytic species are indeed electrocatalysts since the process is favored by the application of either a determined voltage or a certain current density value.

Although different methods have been described for the preparation of specific electrocatalysts for the processes above-mentioned, electrochemical methods have sparked a great interest for this purpose recently since they simplify and improve enormously the production of these materials. For example, new enzyme-free electrodes, based in either oxy/hydroxides or cobalt oxides, have been developed to detect glucose by electrocatalytic oxidation, as a main alternative to the use of electrodes with anchored enzymes which are fabricated via an expensive multi-step process..$^{1,23}$ On the other hand, Premlatha et al. have employed electrodeposited composites of $\mathrm{Co}_{3} \mathrm{O}_{4}$ and multiwalled carbon nanotubes (MWCNT) for this task; ${ }^{25}$ the synergistic

zE-mail: ampsakita@iq.unesp.br; ampsakita@gmail.com; alan.sakita@unesp.br; benedeti@iq.unesp.br behavior between the cobalt oxide and the MWCNT enhances sensitivity and decreases the detection limit significantly. In addition, the use of oxy/hydroxides and alloys of different metals (Co, Ni and $\mathrm{Fe}$ ) is also being explored to improve the electrocatalytic behavior of the corresponding pure-oxides for not only the sensing of different organic molecules (glucose, dopamine or urea) but also OER. Specifically, Matsumoto and Sato ${ }^{26}$ have proved that mixed cobalt oxides containing $\mathrm{La}, \mathrm{Ni}, \mathrm{Fe}, \mathrm{Li}$ or $\mathrm{Sr}$ diminish the resistivity of the main oxide and propose the use of the mixed oxidized species $\mathrm{CoFe}, \mathrm{SrCoFe}^{27}$ and $\mathrm{LaCo}^{28}$ to promote OER.

Aqueous environments are generally chosen for the electrosynthesis of these catalytic materials due to its simplicity, low-toxicity, and economy. ${ }^{29,30}$ Besides, deep eutectic solvents (DES) have been also widely explored as valuable media for the electrodeposition of pure metallic electrocatalysts. ${ }^{31-34}$ However, the potential applicability of DES to electrodeposit directly oxidized active species remains still unexplored. Importantly, the use of DES for this aim might evolve in novel preparation schemes to obtain even more powerful and multifunctional electrocatalysts.

Among all DES, the most frequent employed in electrodeposition is the binary mixture consisting of chloline chloride, a quaternary ammonium salt, and either urea or ethylene glycol, both hydrogen bond donors. For the deposition of metal matrixes with a low content of oxygen, reline and ethaline are commonly used; however, to obtain the corresponding oxidized species, further chemical or electrochemical oxidative steps are required. Interestingly, glyceline, a glycerol-based DES, might be a particularly attractive medium for the electroproduction of deposits with a high oxygen content. In fact, this solvent has already been used for the electrodeposition of cobalt. ${ }^{35}$ In this instance, the formation of oxidized species of cobalt was attributed to the simultaneous reduction of the residual water and $\mathrm{Co}(\mathrm{II})$, and the concomitant spontaneous oxidation of the corresponding metallic film by atmospheric oxygen.

In this work, we have developed an easy and fast electrochemical procedure, involving DES, to obtain, in a single step, supported $\mathrm{Co} / \mathrm{Co}$-oxy/hydroxides deposits exhibiting a multicatalytic activity, e.g. for OER and glucose sensing. Specifically, glyceline has been selected as the electrodeposition medium because not only its composition favors the formation of oxidized species of cobalt but also 


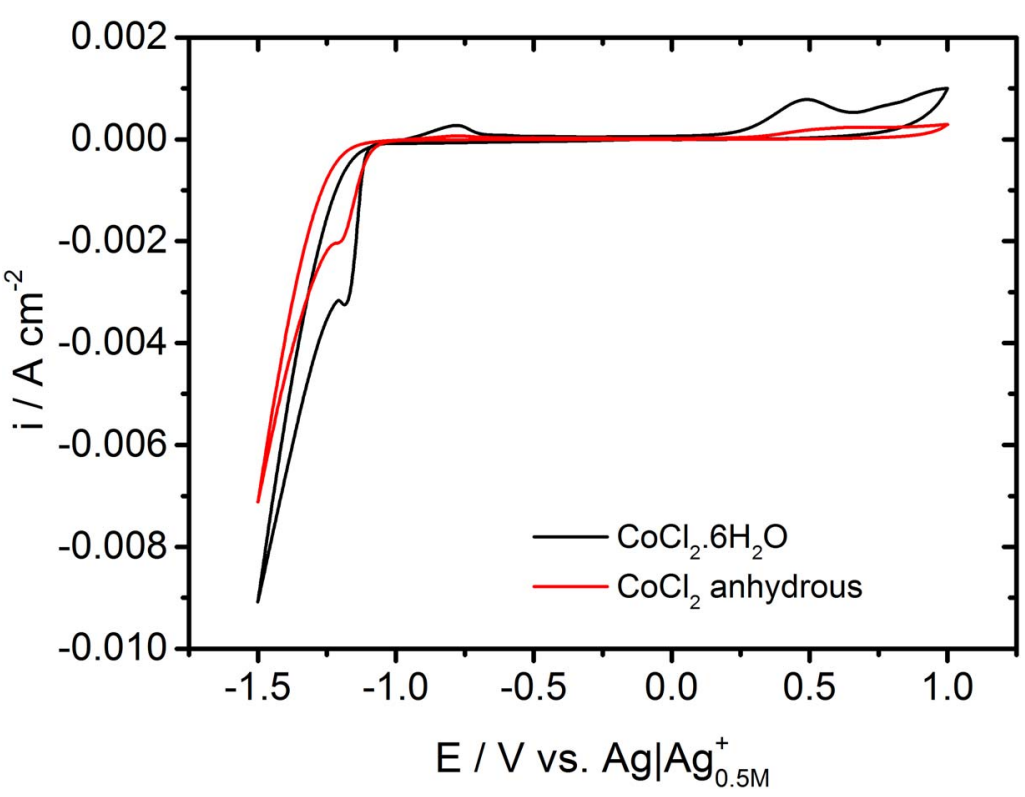

Figure 1. Cyclic voltammograms obtained at $10 \mathrm{mV} \mathrm{s}^{-1}$ in glyceline solution with $0.1 \mathrm{M} \mathrm{CoCl}_{2}$ anhydrous and hydrated. $\mathrm{T}=70^{\circ} \mathrm{C}$. enabled us to investigate the possibilities of this specific DES to obtain electrodeposits different than pure metals or alloys. Indeed, glyceline DES, containing a low and controlled concentration of water, allows the direct electrodeposition of supported $\mathrm{Co} / \mathrm{Co}$-oxy/hydroxides catalysts with the simultaneous formation of a glycerol-based polymeric structure, which incorporates the metallic oxides and plays a key role on the further catalytic activity of the resulting composite. It should be also noticed that no additional thermal treatments are required to obtain the final catalyst. Importantly, the fabricated composites are effective and easily preparable electrocatalysts for different reactions. Actually, our composite materials are useful not only as electrodes in non-enzymatic glucose sensing but also as anodes for OER within water splitting technology.

\section{Experimental}

Reagents and materials.-Chemicals were purchased from commercial sources and used as received. Cobalt chloride hexahydrate was purchased from Alfa Aesar with $99.9 \%$ purity. Glycerol was acquired from Sigma Aldrich with $99.5 \%$ purity. Choline chloride was obtained from Acros Organics with $99 \%$ purity. Sodium hydroxide was purchased from Panreac with USP-NF grade. D-(+)-Glucose was acquired from Merck with reagent European Pharmacopoeia grade. The water used in this work was of Milli-Q quality.

Solvent preparation.-Glyceline DES was prepared by stirring a mixture of choline chloride and glycerol, in a 1:2 molar ratio, at $90^{\circ} \mathrm{C}$ for 4 hours. Then, a colorless and homogeneous solution was obtained. The prepared DES was stored in a vacuum desiccator at room temperature. The electrochemical bath was prepared by stirring glyceline, containing the proper amount of $\mathrm{CoCl}_{2} \cdot 6 \mathrm{H}_{2} \mathrm{O}$, at $90^{\circ} \mathrm{C}$ until the complete dissolution of the cobalt salt.

Electrodeposition of the materials and evaluation of the catalytic activity.-Electrochemical studies were performed with a microcomputer-controlled potentiostat/galvanostat AUTOLAB PGSTAT30 and a GPES software. Electrochemical experiments were carried out in glyceline under $\mathrm{Ar}$ atmosphere, using a three-electrode cell. The reference was an $\mathrm{Ag} \mid \mathrm{Ag}^{+}(0.5 \mathrm{M})$ electrode. ${ }^{35}$ The counter electrode was a Pt|Ti wire. The working electrode was either a glassy carbon (GC) or a Si/Ti/Ni substrate. In all instances, electrodeposition was performed under potentiostatic conditions at $70^{\circ} \mathrm{C}$. All deposits were obtained with an electric charge of $500 \mathrm{mC} \mathrm{cm}^{-2}$.
The catalytic activity of the electrodeposits for glucose detection and water splitting was evaluated. The electrochemical detection of glucose was performed by cyclic voltammetry and chronoamperometry by adding successive volumes of a $0.1 \mathrm{M}$ solution of glucose in aqueous $\mathrm{NaOH}([\mathrm{NaOH}]=0.1 \mathrm{M})$. The performance of the electrodeposits for water splitting, i.e. to promote OER, was tested by recording the polarization curves of a $1 \mathrm{M} \mathrm{NaOH}$ solution at $5 \mathrm{mV} \mathrm{s}^{-1}$ scan rate.

Physical characterization.-Deposits were characterized by field emission scanning electron microscopy (FE-SEM) and Raman, Fourier-transform infrared (FT-IR) and nuclear magnetic resonance (NMR) spectroscopies. FE-SEM images were recorded with a JEOL $\mathrm{J}-7100$ instrument operating with an electron acceleration of $2 \mathrm{keV}$. Raman spectroscopy was performed using a Jobin Yvon-Horiba LabRam HR800 equipment and exciting the sample with the green line of a Nd:YAG laser $\left(\lambda^{\mathrm{Ex}}=532 \mathrm{~nm}\right)$. FT-IR spectra were registered with a Nicolet 6700 FT-IR spectrophotometer from Thermo Scientific, using the attenuated total reflectance sampling technique. ${ }^{1} \mathrm{H}$ NMR spectra were recorded with a $400 \mathrm{MHz}$ Varian Mercury spectrometer.

\section{Results and Discussion}

Preparation and characterization of the electrodeposits.-A representative cyclic voltammogram, recorded on a GC substrate, of a hydrated $\mathrm{CoCl}_{2}$ solution in glyceline DES is shown in Figure 1, by comparing with the cyclic voltammogram with anhydrous $\mathrm{CoCl}_{2}$ in the same medium. The reduction peak around $-1.18 \mathrm{~V}$ is attributed to the $\mathrm{Co}$ (II) reduction to the corresponding metallic phase, which catalyzes the reduction of water present in the DES, i.e. of those water molecules coming from the dissolved salts $\left(\left[\mathrm{H}_{2} \mathrm{O}\right]=0.6 \mathrm{M}\right)$. As a result, cobalt oxides and hydroxides are formed over the first deposited cobalt because of the local $\mathrm{pH}$ variation near the electrode. At more negative potentials, a massive cathodic current related to the solvent is observed; this process does not take place in a blank solution containing only the DES. On the forward scan to positive potentials, a peak at about $-0.8 \mathrm{~V}$ is detected, ascribable to the oxidation of molecular hydrogen adsorbed on the electrode. At more positive potentials (ca. $+0.5 \mathrm{~V}$ ), a signal corresponding to the formation of $\mathrm{Co}$ (III) species is detected. On this basis, it can be stated that some component of the used DES is involved in a reduction process that only takes place when Co and/or Co-oxidized species are formed. Indeed, literature findings reveal that catalyzed reduction processes also occur during the electrodeposition of platinum and cobalt in reline ${ }^{36}$ and glyceline, ${ }^{35}$ respectively. 


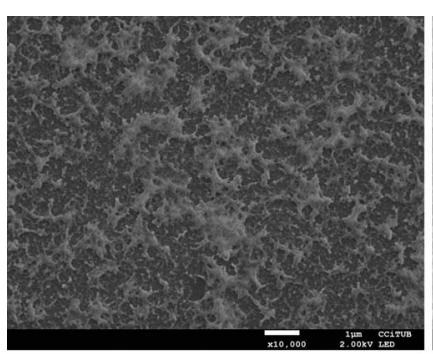

(A)

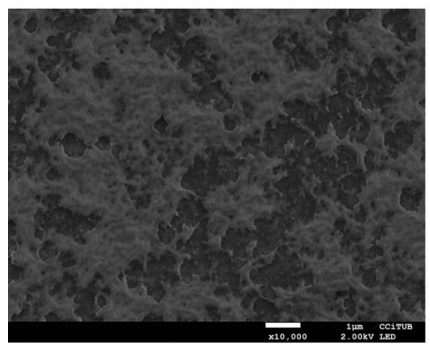

(C)

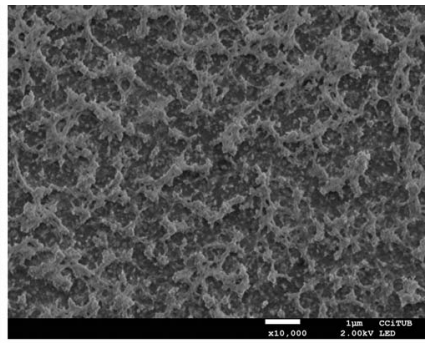

(B)

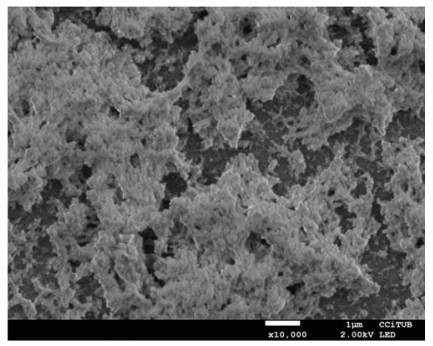

(D)
Figure 2. FE-SEM images of the deposits obtained at $-1.0 \mathrm{~V}$ (A and $\mathrm{C}$ ) and $-1.3 \mathrm{~V}(\mathrm{~B}$ and $\mathrm{D})$ over glassy carbon $(\mathrm{A}$ and $\mathrm{B})$ and $\mathrm{Si} / \mathrm{Ti} / \mathrm{Ni}$ substrates $(\mathrm{C}$ and D). Scale bar $=1 \mu \mathrm{m}$.

FE-SEM images (Figure 2) of the deposits prepared at different potentials and over two distinct substrates, i.e. $\mathrm{GC}$ and $\mathrm{Si} / \mathrm{Ti} / \mathrm{Ni}$ pieces, reveal a main fluffy (sponge) structure. Furthermore, EDS spectra (Figure S1) evidence the presence of metallic Co and a significant amount of oxygen, coming from the Co-oxidized species. Moreover, an intense peak corresponding to carbon is also detected, even when the deposit is formed over $\mathrm{Si} / \mathrm{Ti} / \mathrm{Ni}$ substrates. Therefore, such signal cannot be attributed to the carbonaceous nature of the GC substrate. Also, another important information is the charging and burning of the samples during FE-SEM analysis related to their low conductivity and decomposition due to the interaction with the electron beam, respectively. In this regard, besides metallic cobalt and the corresponding oxides, the formation of organic species may occur during the electrodeposition step.

In order to get insight into the processes observed in the voltammetric response, the electrodeposits prepared between -1.0 and $-1.3 \mathrm{~V}$ were posteriorly oxidized by means of a linear voltammetric scan (Figure S2). On one hand, the deposits obtained at less negative potentials $(-1.0 \mathrm{~V}$ and $-1.1 \mathrm{~V})$ oxidize at about $-0.1 \mathrm{~V}$, i.e. a potential corresponding to the oxidation of metallic cobalt. On the other hand,

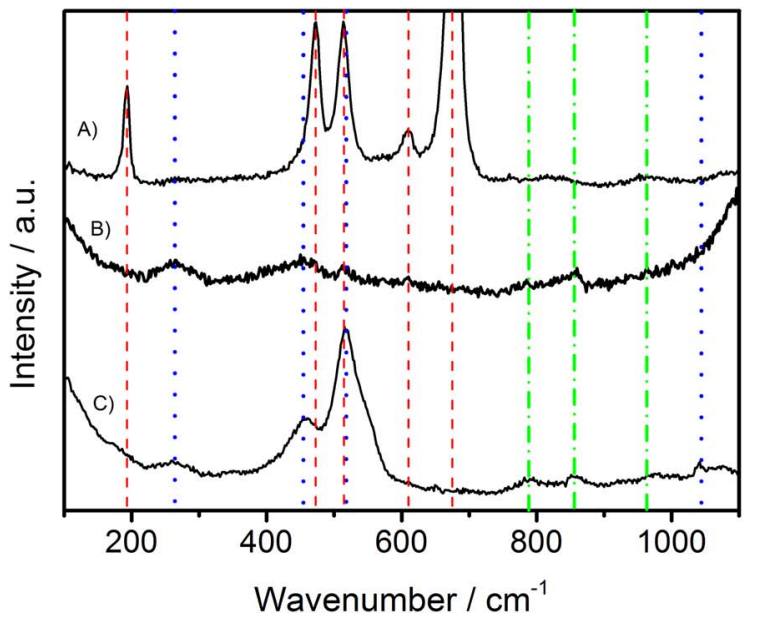

those deposits formed at more negative potentials within this range $(-1.2 \mathrm{~V}$ and $-1.3 \mathrm{~V})$ mainly oxidize at potentials higher than $+0.5 \mathrm{~V}$, in a peak associated to the oxidation of $\mathrm{Co}$ (II) to $\mathrm{Co}$ (III). It should be noticed that such oxidation signal becomes more intense when the potential applied during the electrodeposition step is more negative. This oxidation peak has been also observed by Suryanto et al. ${ }^{37}$ and Sakita et al. ${ }^{35}$ who attributed it to the oxidation of cobalt oxides formed in protic ionic liquids. In this sense, and comparing with other DESs, glyceline exhibits an unusual behavior for the deposition of cobalt since distinct oxidized species, besides the metallic ones, are formed during the process. Interestingly, the proportion of such oxidized species is more significant as the deposition potential applied is more negative. However, $\mathrm{Li}$ and $\mathrm{col}^{38}{ }^{38}$ demonstrated the electrodeposition of only metallic cobalt in reline DES.

Raman spectra of the electrodeposits obtained at -1.0 and $-1.3 \mathrm{~V}$ over GC and $\mathrm{Si} / \mathrm{Ti} / \mathrm{Ni}$ substrates are shown in Figures 3 and S3. The Raman spectrum of a deposit obtained at $-1.0 \mathrm{~V}$ over a GC electrode (A in Figure 3) shows peaks at 194, 467, 512, 608 and $676 \mathrm{~cm}^{-1}$ (marked with red dashed lines in Figure 3), ascribed mainly to the presence of $\mathrm{Co}_{3} \mathrm{O}_{4}$ oxides. ${ }^{35,39}$ On the other hand, the spectrum of an analogous deposit obtained at $-1.3 \mathrm{~V}$ (B in Figure 3) displayed two additional sets of less intense peaks: one related to the formation of $\mathrm{Co}(\mathrm{OH})_{2}{ }^{39,40}$ (peaks at 261, 453, 517 and $1042 \mathrm{~cm}^{-1}$ and marked with blue dotted lines in Figure 3) and another attributed to organic products formed on the electrode surface (marked in green dot-lines in Figure 3). In order to avoid the noise signal of the glassy carbon substrate and get more reliable spectroscopic data, the Raman spectrum (C in Figure 3 and Figure S3) of an electrodeposit prepared at $-1.3 \mathrm{~V}$ over a $\mathrm{Si} / \mathrm{Ti} / \mathrm{Ni}$ substrate was also recorded. In this case, the peaks corresponding to the presence of both cobalt hydroxide and organic products were detected.

In order to verify and comprehend the formation of organic products over the electrode surface, the electrodeposits were analyzed further by means of both FT-IR and ${ }^{1} \mathrm{H}$ NMR spectroscopies. FT-IR spectra (D-F in Figure 3 ) of the deposits formed over GC and Si/Ti/Ni substrates show essentially the same spectroscopic signature. In all instances, five characteristic signals are detected. First, a broad band between 3700 and $2500 \mathrm{~cm}^{-1}$, centered at ca. $3350 \mathrm{~cm}^{-1}$, attributed to $\mathrm{O}-\mathrm{H}$ stretching. Second, two signals peaking at 2865 and $2933 \mathrm{~cm}^{-1}$, associated to the $\mathrm{C}-\mathrm{H}$ stretching vibrations of the hydrocarbonated skeleton of the organic matrix. Third, a low intensity signal around $1630 \mathrm{~cm}^{-1}$ attributed its $\mathrm{O}-\mathrm{H}$ bending modes. Fourth, a broad signal located between 1500 and $1300 \mathrm{~cm}^{-1}$, related to bending vibrations of the $\mathrm{C}-\mathrm{O}$ bonds of the macromolecule. And finally, a peak at ca. $1050 \mathrm{~cm}^{-1}$, corresponds to the $\mathrm{C}-\mathrm{O}$ stretching. The bands detected in the FT-IR spectra and their assignment are in perfect agreement with previous literature reports. ${ }^{41-43}$ The signals observed around $620 \mathrm{~cm}^{-1}$

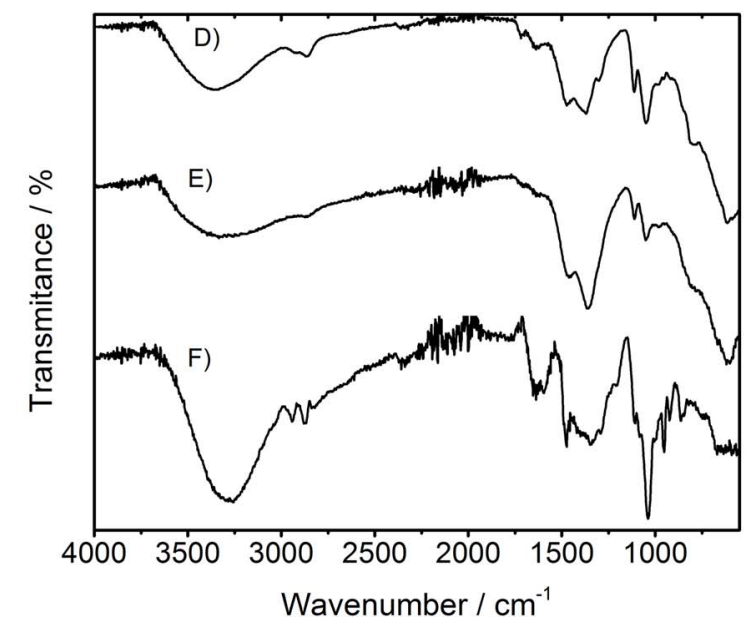

Figure 3. Raman (A-C) and FT-IR (D-F) spectra of deposits obtained at $-1.0 \mathrm{~V}(\mathrm{~A}, \mathrm{D}$ and $\mathrm{E})$ and $-1.3 \mathrm{~V}(\mathrm{~B}, \mathrm{C}$ and F) over GC (A, B and D) and Si/Ti/Ni substrates $(\mathrm{C}, \mathrm{E}$ and $\mathrm{F})$. 


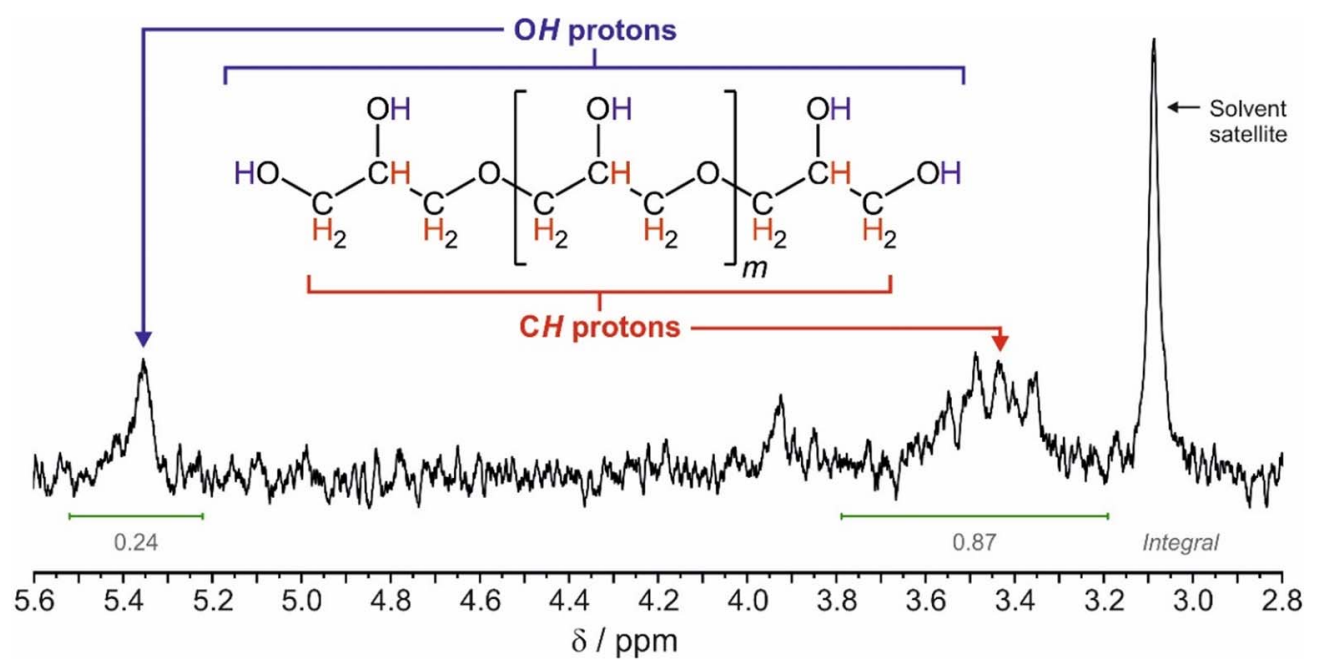

Figure 4. ${ }^{1} \mathrm{H}$ NMR spectrum in $d_{3}$-acetonitrile of the polymeric composite deposited at $-1.0 \mathrm{~V}$ over a GC electrode. The assignment of the peaks to the different hydrogen atoms located in the distinct environments within the poly-glycerol structure is also indicated.

are assigned to $\mathrm{Co}-\mathrm{O}$ stretching modes of vibration, ${ }^{44}$ in agreement with those observed in the Raman spectra depicted in Figure 3. Thus, FT-IR spectroscopy reveals that the carbonaceous compound, present on the substrate surface and formed during the electrodeposition, must be formed from the glycerol present in glyceline.

${ }^{1} \mathrm{H}$ NMR was employed to confirm the formation of a glycerolbased polymer during the electrodeposition step at negative potentials. The ${ }^{1} \mathrm{H}$ NMR spectrum (Figure 4 ) of the organic film deposited over a GC electrode at a cathodic potential of $-1.0 \mathrm{~V}$ was recorded by dissolving the sample in deuterated acetonitrile. Although the resolution of the NMR spectrum is low, due to the very small amount of polymer formed, two characteristic signals can be clearly detected: a singlet peak at $5.4 \mathrm{ppm}$ and a broad multiplet signal located between 3.3 and $3.7 \mathrm{ppm}$. Literature findings reveal that these two NMR resonances can be attributed to those protons of the hydroxyl groups of a polymeric structure of glycerol and those attached to the carbon atoms adjacent to the $\mathrm{OH}$ groups, respectively, as it has been reported for poly-glycerol. ${ }^{45,46}$

FT-IR and NMR spectroscopies suggest the formation of polyglycerol during electrodeposition, in such a way that a polyglycerol/Co/Co-oxy/hydroxides composite is formed on the electrode surface. On one hand, in the initial steps of the process, the nucleation and growth of the cobalt metallic phase occurs, as expected for a metal deposition, followed by the reduction of the solvent, which induces the growth of the corresponding oxide and hydroxide. It should be noted that the presence of water $\left(\left[\mathrm{H}_{2} \mathrm{O}\right]=0.6 \mathrm{M}\right)$ in the electrochemical bath (coming from the cobalt salt), produces a high increase of the current on the Cottrellian zone of the i-t transients (Fig S1) in comparison with solutions exhibiting a low water content. ${ }^{35} \mathrm{On}$ the other hand, the presence of Co(III) species in the formed electrodeposits, as revealed by Raman spectroscopy, allows us proposing a cobalt-mediated free radical polymerization pathway for the formation of polyglycerol, where Co(II) complexes are trapped by the radicals and produce new cobalt (III)-based ones. ${ }^{47}$ According to this mechanism, the production of this organic polyol is induced by the generation of glycerol radicals during the reducing process, ${ }^{48}$ which leads to the formation of several by-products by alkaline dehydration. In the next step, hydrogenation ${ }^{49,50}$ occurs, which promotes further polymerization. It should be mentioned that this mechanism requires acidic conditions to assist the dehydration of glycerol, which explains the formation of $\mathrm{Co}_{3} \mathrm{O}_{4}$ at less negative potentials, where less current attributed to water reduction is observed. Accordingly, in this case, the cobalt-mediated radical polymerization should be the mechanism leading to the formation of polyglycerol during the deposition process.
The polymer formed on both $\mathrm{GC}$ and $\mathrm{Si} / \mathrm{Ti} / \mathrm{Ni}$ substrates can be partially removed from the electrodeposit by means of a pretreatment in ethanol for 1 hour. FE-SEM images (Figure 5) of the treated deposits show that, after a partial removal of the polymeric material, the Co-oxo/hydroxides exhibit a granular underlayer composed by nanosized grains (average value of $20 \mathrm{~nm}$ on GG and $35 \mathrm{~nm}$ on $\mathrm{Si} / \mathrm{Ti} / \mathrm{Ni}$, respectively).

In summary, the selected DES allows to obtain polymer/Co/Cooxy/hydroxides composites; the proportion of each component depends on the voltage applied during their electrodeposition. Specifically, deposits prepared at ca. $-1.0 \mathrm{~V}$ present a low polymer content and are mainly composed by Co(II,III) oxides, whereas those prepared at more negative potentials $(-1.3 \mathrm{~V})$ display a higher proportion of polymer in conjunction with $\mathrm{Co}(\mathrm{II}, \mathrm{III})$ hydroxides. In all cases, the initial deposition of cobalt catalyzes the reduction of water, thereby modifying the local $\mathrm{pH}$ around the electrode and promoting the formation of $\mathrm{Co}$ (II)-oxy/hydroxides and the polymerization of glycerol.

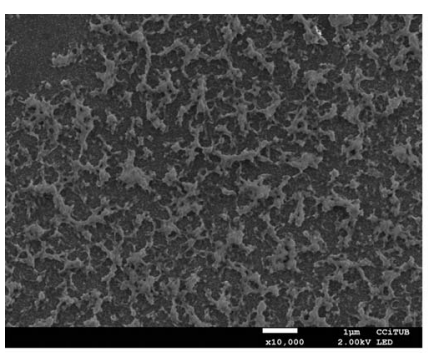

(A)

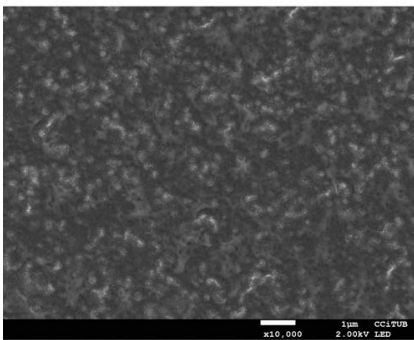

(C)

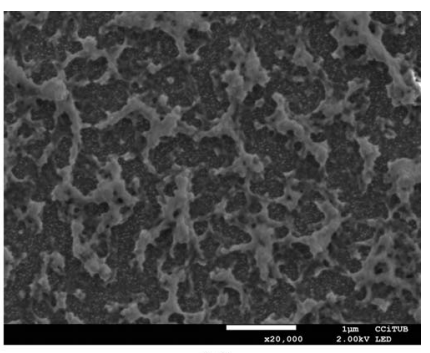

(B)

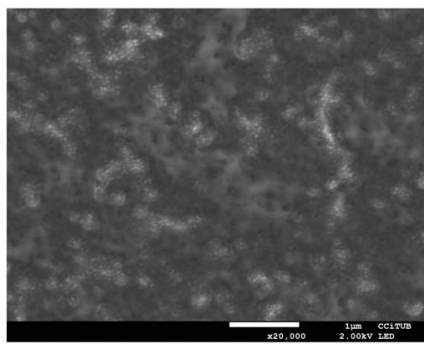

(D)
Figure 5. FE-SEM images of deposits obtained at $-1.0 \mathrm{~V}$ on GC (A and $\mathrm{B}$ ) and $\mathrm{Si} / \mathrm{Ti} / \mathrm{Ni}(\mathrm{C}$ and $\mathrm{D})$ substrates after treatment in ethanol for 1 hour. Scale bar $1 \mu \mathrm{m}$. 


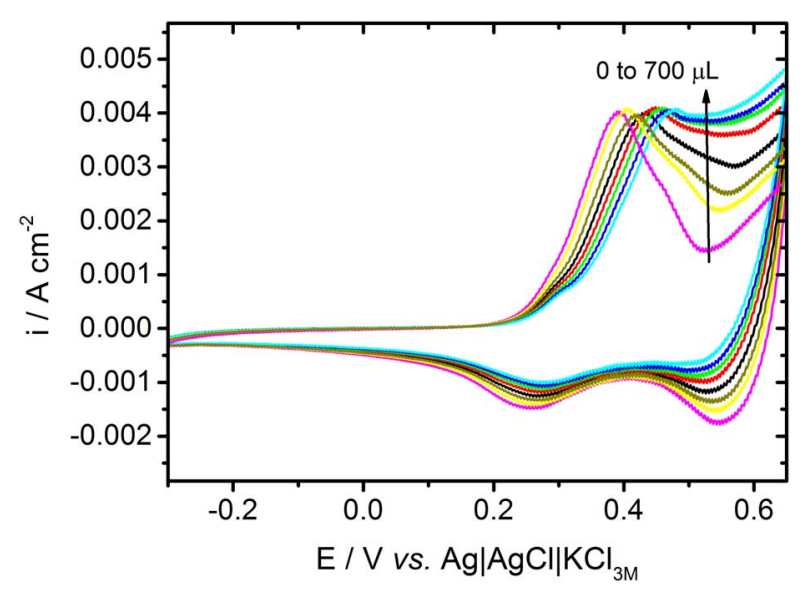

Figure 6. Cyclic voltamograms obtained in $0.1 \mathrm{M} \mathrm{NaOH}$ over the deposit obtained at $-1.0 \mathrm{~V}$ on glassy carbon (untreated), with successive additions of $100 \mu \mathrm{L}$ of $0.1 \mathrm{M} \mathrm{NaOH}+0.1 \mathrm{M}$ glucose (concentration around $0.39 \times$ $10^{-3} \mathrm{M}$ per addition).

Applicability of the electrodeposits.-The applicability of the fabricated composites as multifunctional catalysts has been evaluated by testing their performance for glucose sensing and OER in alkaline medium.

Electrochemical performance for glucose sensing.-The potential oxidation of glucose on the composites was tested by cyclic voltammetry. The voltammetric profile of the composites in $0.1 \mathrm{M}$ $\mathrm{NaOH}$ aqueous solution (Figure 6, pink line) shows a clear oxidation peak attributed to the oxidation of $\mathrm{Co}$ (II) to $\mathrm{Co}(\mathrm{III})$ at about $+0.4 \mathrm{~V}$. When an alkaline solution of glucose is added, the current recorded within the potential range between +0.5 and $+0.6 \mathrm{~V}$ clearly increases. Thus, this experiment confirms the possibility to oxidize glucose on the prepared electrodes. Glucose oxidation is not detected on bare GC or $\mathrm{Si} / \mathrm{Ti} / \mathrm{Ni}$ substrates revealing, thus, the catalytic effect of $\mathrm{Co}(\mathrm{III})$ present in the fabricated composites. The current arising from glucose oxidation gradually increases with glucose concentration as expected. A similar voltammetric behavior is reported in the works of Kung ${ }^{23}$ and Kang ${ }^{51}$ for the enzyme-free electrochemical sensing of glucose with cobalt oxides nanostructures.

The potential of the prepared composites for glucose sensing was also explored by chronoamperometric methods. For this purpose, a constant voltage of $+0.6 \mathrm{~V}$ ( $\mathrm{vs} \mathrm{Ag}|\mathrm{AgCl}| \mathrm{KCl}_{3 \mathrm{M}}$ ) was applied to a $\mathrm{GC}$ electrode containing the composite. The corresponding chronoamper- ometric curves (Figure 7A) reveal a gradual increase of the oxidation current as the glucose concentration increases in the electrode surroundings. All composites tested, i.e. those prepared at $-1.0 \mathrm{~V}$ or $-1.3 \mathrm{~V}$, and without or with partial dissolution of the polymer, can detect and quantify glucose, with correct calibration curves (Figure 7B). Both the limit of detection and sensitivity found for the cobaltbased materials reported in this work are compared to those of other distinct materials reported in the literature (see Table S1). It should be stressed out at this point that the electrodes deposited in glyceline reveal good results in comparison with pure cobalt based electrodes for low concentration range and furthermore exhibit no need to employ a heat-treatment or an annealing process. Moreover, the possibility of using directly the poly-glycerol/Co/Co-oxy/hydroxides composites (supported catalytic species) prepared in the one-step electrochemical procedure as electrodes for non-enzymatic amperometric glucose sensor drastically simplifies the sensor fabrication.

Catalytic activity for the oxygen evolution reaction.-The effectiveness of the deposited composites as catalysts for the oxygen evolution reaction in alkaline medium has been evaluated by recording the polarization curves in an $1 \mathrm{M} \mathrm{NaOH}$ aqueous solution at $5 \mathrm{mV} \mathrm{s}^{-1}$ (Figure 8A). The different characteristic parameters, namely, the onset potential, Tafel slopes and overpotential at $10 \mathrm{~mA} \mathrm{~cm}^{-2}$ are collected in Table I. Remarkably, the partial removal of the polymeric matrix from the electrode surface and subsequent liberation of the metallic oxides result in a dramatic enhancement of the catalytic activity of the composite for both employed substrates. Such feature is clearly evidenced by the lower overpotential at $10 \mathrm{~mA} \mathrm{~cm}^{-2}$. The better OER performance in deposited materials treated with ethanol for 1 hour suggests the non-conducting properties of the polymeric matrix codeposited on the electrode and, thereby, that the matrix decreases the catalytic ability of the deposits, increasing the overpotential at $10 \mathrm{~mA}$ $\mathrm{cm}^{-2}$ from 334 to $358 \mathrm{mV}$. Similarly, the Tafel slope also drops from ca. 120 to $80 \mathrm{mV} \mathrm{dec}^{-1}$ when the polymer is removed from the electrode surface, indicating that the mechanism of the OER changes in the presence of the polymer, becoming less kinetically-favorable and impeding catalysis. ${ }^{52,53}$ It should be also highlighted that the stability of the deposit obtained onto $\mathrm{Si} / \mathrm{Ti} / \mathrm{Ni}$ substrates at $-1.0 \mathrm{~V}$ was evaluated by submitting them to several hours of electrolysis; all the analyzed deposits reveal a good stability after 3 hours of electrolysis (Fig. 8C).

The best catalytic electrodeposited material, i.e. obtained at $-1.0 \mathrm{~V}$ on $\mathrm{Si} / \mathrm{Ti} / \mathrm{Ni}$ substrate and treated in ethanol, was compared with cobaltbased electrodes developed in other works (Table S1), which reveals that the cobalt oxy/hydroxides prepared using DES depicts an excellent response for a material synthetized by electrodeposition employing low charge density. Moreover, a simple method and a novel
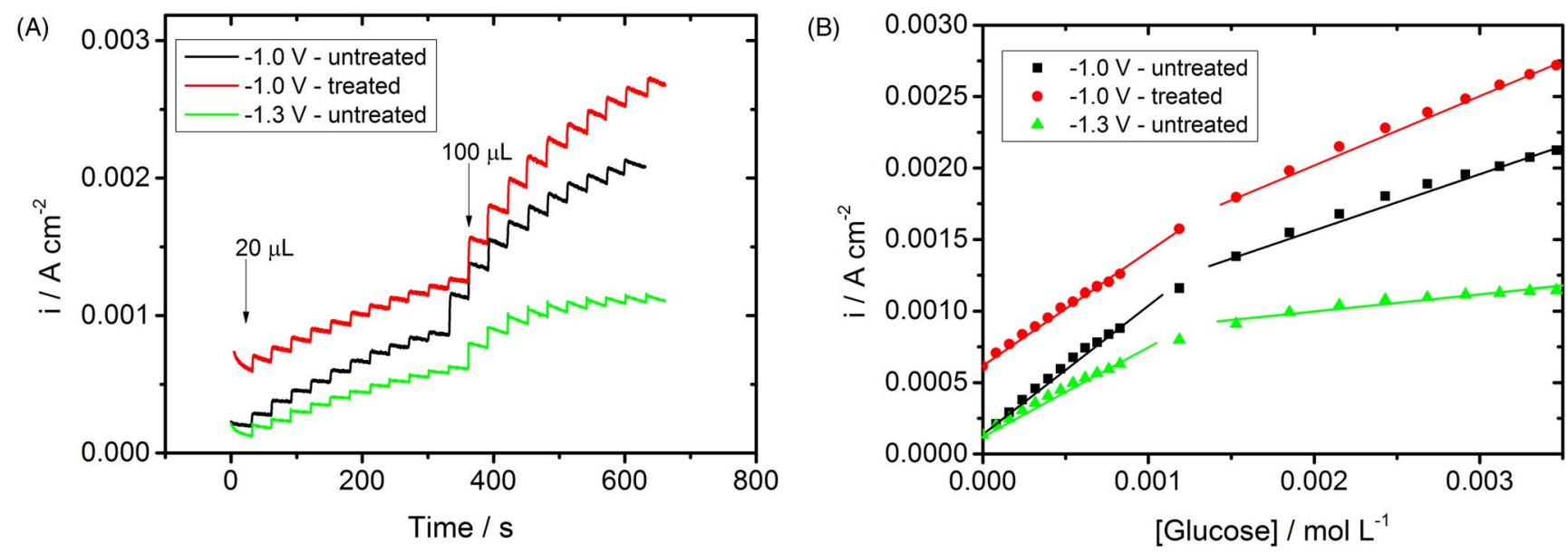

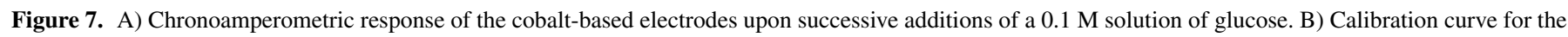
different cobalt-based electrodes in terms of current density vs. glucose concentration. 

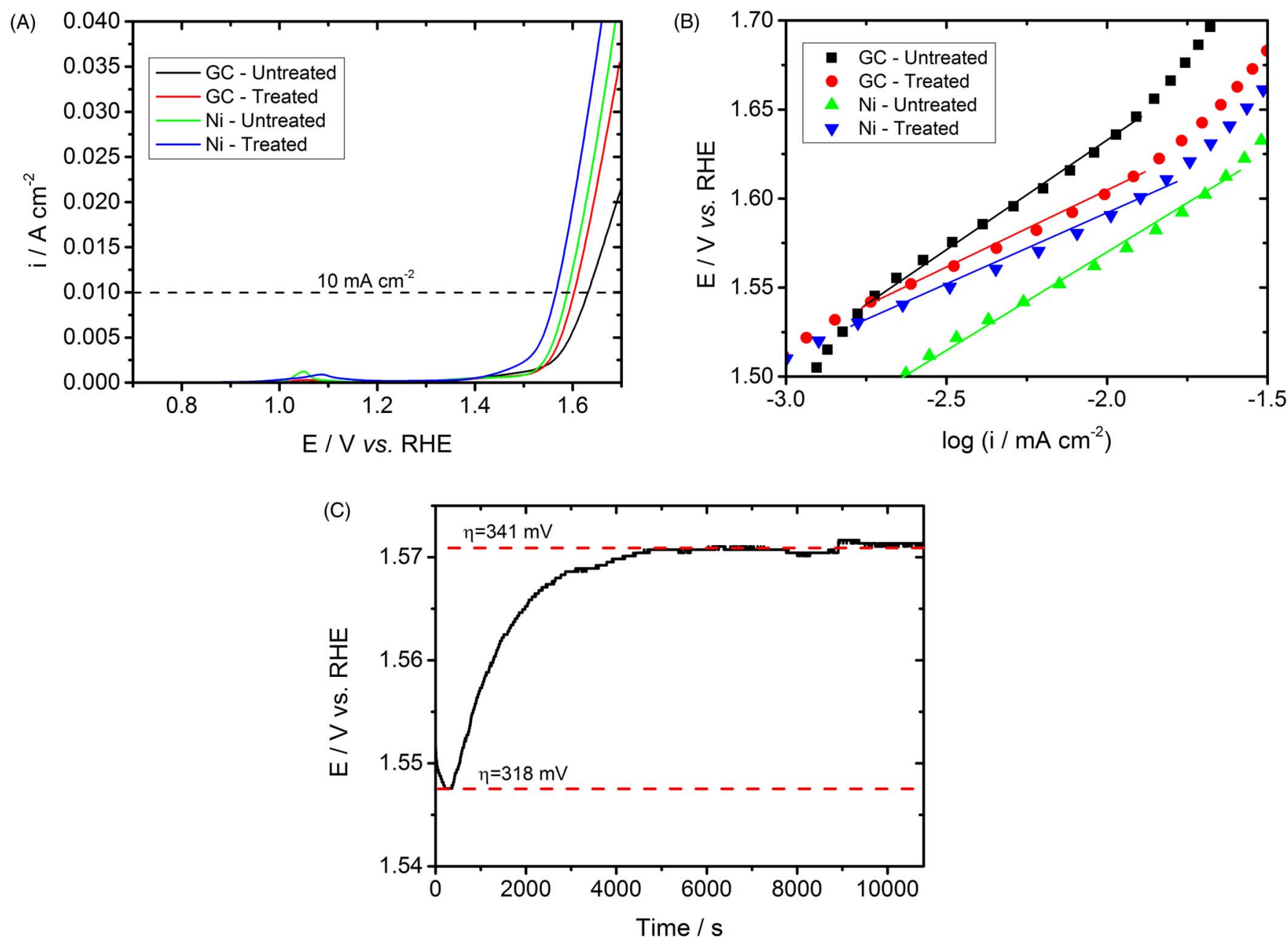

Figure 8. A) Polarization curves, B) Tafel plot for deposits obtained at $-1.0 \mathrm{~V}$ on different substrates and treatments in $1 \mathrm{M} \mathrm{NaOH} \mathrm{solution} \mathrm{at} 5 \mathrm{mV} \mathrm{s}^{-1}$ and C) E-t curve recorded during 3 hours at $10 \mathrm{~mA} \mathrm{~cm}^{-2}$.

approach to deposit oxy/hydroxides utilizing deep eutectic solvents has been successfully performed by the first time, paving the way for the development of composites by electrodeposition.

\section{Conclusions}

The use of glyceline DES, containing a low and controlled proportion of water, allowed us to electrodeposit, through a one-step easy and fast procedure, a thin film of poly-glycerol/Co/Co-oxy/hydroxides composite, where the Co oxidized species are in the form of nanometric grains. This is a novel electrochemical procedure for the fabrication of catalytic species of cobalt, easier and faster than the usual fabrication procedures requiring first inorganic synthesis or electrochemical deposition of metallic cobalt, second a posterior thermic or electrochemical treatment to obtain the catalytic cobalt oxides, and third, the supporting of the catalytic species on a new material. The glyceline
DES, which has been previously used to electrofabricate only silver and copper structures, can be, therefore, proposed to the electrosynthesis of oxides/hydroxides of metals as cobalt. The mechanism of formation of the poly-glycerol/Co/Co-oxy/hydroxides composite implies the initial electrodeposition of some metallic cobalt, which catalyses the reduction of the contained water generating hydroxyl ions leading to $\mathrm{Co}$ (II) Oxy/hydroxides. The presence of water and cobalt (II) oxides initiate glycerol polymerization and finally the formation of the composite, as the manner that $\mathrm{Co}$ (II), $\mathrm{Co}$ (III)-oxy/hydroxides are formed, close to the fluffy polymeric lattice.

The poly-glycerol/Co/ Co(II,III)-oxy/hydroxides composite is proposed as a multi-functional catalysts because enhances both glucose oxidation and oxygen evolution reaction. The composite has been demonstrated as a useful electrode for glucose non-enzymatic amperometric sensors, with a good linearity of the intensity-glucose concentration, in alkaline medium, and a significant sensitivity, up to

Table I. Performance of the prepared electrodes for glucose sensing and OER.

\begin{tabular}{|c|c|c|c|c|c|}
\hline Composite & $\begin{array}{c}\text { Sensitivity/ } \\
\mu \mathrm{A} \mathrm{mM}^{-1} \mathrm{~cm}^{-2}\end{array}$ & $\mathrm{LOD} / \mu \mathrm{M}$ & $\begin{array}{c}\mathrm{E}_{\text {onset }} \text { for } \\
\text { OER (vs RHE) }\end{array}$ & $\begin{array}{c}\text { Overpotential } \\
\text { (at } 10 \mathrm{~mA} \mathrm{~cm}^{-2} \text { ) }\end{array}$ & $\begin{array}{c}\text { Tafel } \\
\text { Slope/mV dec }\end{array}$ \\
\hline$-1.0 \mathrm{~V}$ GC Untreated & 903 & 0.08 & 1.56 & 0.400 & 121 \\
\hline$-1.0 \mathrm{~V}$ GC Treated & 760 & 0.02 & 1.57 & 0.374 & 87 \\
\hline$-1.0 \mathrm{~V} \mathrm{Ni}|\mathrm{Ti}| \mathrm{Si}$ Untreated & - & - & 1.55 & 0.359 & 104 \\
\hline$-1.0 \mathrm{~V} \mathrm{Ni}|\mathrm{Ti}| \mathrm{Si}$ Treated & - & - & 1.53 & 0.334 & 82 \\
\hline
\end{tabular}


$900 \mu \mathrm{A} \mathrm{mM}^{-1} \mathrm{~cm}^{-2}$. The prepared composite also reveals to be a good and stable anode for OER, with Tafel and overpotential values of $82 \mathrm{mV} \mathrm{dec}^{-1}$ and $334 \mathrm{mV}$, respectively. Furthermore, the deposition employing low charge density $\left(500 \mathrm{mC} \mathrm{cm}^{-2}\right)$ has been able to produce multifunctional thin films composites.

\section{Acknowledgment}

The authors thank the Brazilian founding CAPES (proc. no. 88881.132671/2016-01), CNPq (proc.no. 141257/2014-8), Portuguese FCT (project PEst-OE/QUI/UI0100/2013), EU ERDF (FEDER) and the Spanish Government grants (TEC2014-51940C2-R). The authors thank the CCiT-UB for the use of their equipment.

\section{ORCID}

Alan M. P. Sakita (D https://orcid.org/0000-0001-6992-9334 Assis V. Benedetti (D) https://orcid.org/0000-0002-0243-6639

\section{References}

1. S. Park, H. Boo, and T. D. Chung, Anal. Chim. Acta, 556, 46 (2006).

2. B. M. Hunter, H. B. Gray, and A. M. Müller, Chem. Rev., 116, 14120 (2016).

3. Q. Liu et al., Int. J. Hydrogen Energy, 42(8), 5560 (2017).

4. X. Zhang et al., Sci. Rep., 7, 43590 (2017).

5. Y. Hou et al., Energy Environ. Sci., 9, 478 (2016).

6. J. Geng, L. Kuai, E. Kan, Q. Wang, and B. Geng, ChemSusChem, 8, 659 (2015).

7. I. Gurrappa and L. Binder, Sci. Technol. Adv. Mater., 9, 043001 (2008).

8. L. P. Bicelli, B. Bozzini, C. Mele, and L. D’Urzo, Int. J. Electrochem. Sci., 3, 356 (2008).

9. D. R. Rolison et al., Chem. Soc. Rev., 38, 226 (2009).

10. Q. F. Zhou, L. Y. Lu, L. N. Yu, X. G. Xu, and Y. Jiang, Electrochim. Acta, 106, 258 (2013).

11. T. Zhao and Z. Kang, J. Electrochem. Soc., 163, D628 (2016).

12. Z.-L. Wang, R. Guo, L.-X. Ding, Y.-X. Tong, and G.-R. Li, Sci. Rep., 3, 1204 (2013).

13. B. M. Hunter, W. Hieringer, J. R. Winkler, H. B. Gray, and A. M. Müller, Energy Environ. Sci., 9, 1734 (2016).

14. Y. Li, M. Zhao, Y. Zhao, L. Song, and Z. Zhang, Part. Part. Syst. Charact., 33, 158 (2016).

15. D. Tang et al., ACS Appl. Mater. Interfaces, 6, 7918 (2014).

16. M. Gong et al., J. Am. Chem. Soc., 135, 8452 (2013).

17. Y. Zhao et al., Electrochim. Acta, 145, 148 (2014).

18. J. W. D. Ng, M. Tang, and T. F. Jaramillo, Energy Environ. Sci., 7, 2017 (2014).
19. J. Macdonald, B. Gualtieri, N. Runga, E. Teliz, and C. Zinola, Int. J. Hydrogen Energy, 33, 7048 (2008).

20. S. G. Kandalkar, D. S. Dhawale, C. Kim, and C. D. Lokhande, Synth. Met., 160, 1299 (2010).

21. Y. Wang, H. Wang, and X. Wang, Electrochim. Acta, 92, 298 (2013).

22. X. Hu, X. Lin, Z. Ling, Y. Li, and X. Fu, Electrochim. Acta, 138, 132 (2014).

23. C. W. Kung, C. Y. Lin, Y. H. Lai, R. Vittal, and K. C. Ho, Biosens. Bioelectron., 27, 125 (2011).

24. K. K. Lee, P. Y. Loh, C. H. Sow, and W. S. Chin, Electrochem. commun., 20, 128 (2012).

25. S. Premlatha, P. Sivasakthi, and G. N. K. Ramesh Bapu, RSC Adv., 5, 74374 (2015).

26. Y. Matsumoto and E. Sato, Mater. Chem. Phys., 14, 397 (1986).

27. A. Grimaud et al., Nat. Commun., 4, 1 (2013).

28. A. Vignesh, M. Prabu, and S. Shanmugam, ACS Appl. Mater. Interfaces, 8, 6019 (2016).

29. B. Tang and K. H. Row, Monatshefte fur Chemie, 144, 1427 (2013).

30. E. L. Smith, A. P. Abbott, and K. S. Ryder, Chem. Rev., 114, 11060 (2014).

31. A. P. Abbott, G. Capper, K. J. McKenzie, and K. S. Ryder, J. Electroanal. Chem., 599, 288 (2007).

32. P. Guillamat, M. Cortés, E. Vallés, and E. Gómez, Surf. Coatings Technol., 206, 4439 (2012).

33. Y. H. You, C. D. Gu, X. L. Wang, and J. P. Tu, Surf. Coatings Technol., 206, 3632 (2012).

34. E. Gómez, P. Cojocaru, L. Magagnin, and E. Valles, J. Electroanal. Chem., 658, 18 (2011).

35. A. M. P. Sakita, R. Della Noce, C. S. Fugivara, and A. V. Benedetti, Phys. Chem. Chem. Phys., 18, 25048 (2016).

36. E. Gomez and E. Valles, Int. J. Electrochem. Sci., 8, 1443 (2013)

37. B. H. R. Suryanto, X. Lu, H. M. Chan, and C. Zhao, RSC Adv., 3, 20936 (2013).

38. M. Li, Z. Wang, and R. G. Reddy, Electrochim. Acta, 123, 325 (2014).

39. J. Yang, H. Liu, W. N. Martens, and R. L. Frost, J. Phys. Chem. C, 114, 111 (2010).

40. R. Della Noce, S. Eugénio, T. M. Silva, M. J. Carmezim, and M. F. Montemor, J. Power Sources, 288, 234 (2015)

41. M. Jahandar, A. Zarrabi, M. A. Shokrgozar, and H. Mousavi, Mater. Res. Express, 2, 125002 (2015).

42. Y. Shen, G. He, Y. Guo, H. Xie, and W. Fang, Nanoscale Res. Lett., 12, 525 (2017).

43. C. Ardila-Suárez, D. Rojas-Avellaneda, and G. E. Ramirez-Caballero, Int. J. Polym. Sci., 2015 (2015).

44. T. Zhao, H. Jiang, and J. Ma, J. Power Sources, 196, 860 (2011).

45. E. Schwab and S. Mecking, J. Polym. Sci. Part A Polym. Chem., 43, 4609 (2005).

46. D. Wilms, J. Nieberle, J. Klos, H. Löwe, and H. Frey, Chem. Eng. Technol., 30, 1519 (2007).

47. A. Debuigne, R. Poli, C. Jérôme, R. Jérôme, and C. Detrembleur, Prog. Polym. Sci, 34, 211 (2009).

48. S. Kongjao, S. Damronglerd, and M. Hunsom, J. Appl. Electrochem., 41, 215 (2011).

49. K. Okada, Ph.D. Thesis, University of Michigan (2013).

50. T. Miyazawa, Y. Kusunoki, K. Kunimori, and K. Tomishige, J. Catal., 240, 213 (2006).

51. L. Kang, D. He, L. Bie, and P. Jiang, Sensors Actuators, B Chem., 220, 888 (2015)

52. P. T. Babar et al., Appl. Surf. Sci., 427, 253 (2018).

53. S. Du et al., Chem. Commun., 51, 8066 (2015). 